Fangfang Zhao, NANJING NORMAL UNIVERSITY, fangfangzhao@njnu.edu.cn Gillian Roehrig, UNIVERSITY OF MINNESOTA, roehr013@umn.edu Lorelei Patrick, FORT HAYS STATE UNIVERSITY, lepatrick@fhsu.edu Chantal Levesque-Bristol, PURDUEUNIVERSITY,cbristol@purdue.edu Sehoya Cotner, UNIVERSITY OF MINNESOTA, UNIVERSITY OF BERGEN, sehoya@umn.edu

\title{
Using a Self-Determination Theory Approach to Understand Student Perceptions of Inquiry-Based Learning
}

\begin{abstract}
Inquiry-based laboratory activities, as a part of science curricula, have been advocated to increase students' learning outcomes and improve students' learning experiences, but students sometimes struggle with open-inquiry activities. This study aims to investigate students' perceptions of inquiry-based learning in a set of laboratory activities, specifically from a psychological (i.e., Self-Determination Theory) perspective. Students' ratings of the level of inquiry in these activities indicate that students' perceptions of inquiry align with the instructorintended amount of inquiry in each exercise. Students' written responses, explaining their ratings, indicate that students' perceptions of the amount of inquiry in a given lab exercise relate to their feeling of freedom (or autonomy), competence, and relatedness (or support), during the inquiry-based learning activities. The results imply that instructors implementing inquiry-based learning activities should consider student motivation, and Self-Determination Theory can be a useful diagnostic tool during teaching development.
\end{abstract}

\section{KEYWORDS}

inquiry-based learning, Self-Determination Theory (SDT), student perceptions, laboratory activities

\section{INTRODUCTION}

According to Kolb's (Kolb and Kolb 2005) model of experiential learning, students learn best through a cycle that involves experience, reflective observation, abstract conceptualization, and active experimentation. In science education, experiential learning takes the form of inquiry-based activities (Abdulwahed and Nagy 2009; Ferri et al. 2016; Rosen et al. 2019), which have been advocated in science learning environments for decades (Riga et al. 2017). While traditional science teaching has tended to focus on the accumulation of scientific facts, inquiry requires students to do science as practiced by the scientific community (NRC 1996). By learning science in the way scientists do science, students can develop their interests, as well as acquire knowledge and skills (NRC 1996; Riga et al. 2017). While existing research has shown that inquiry-based strategies can be a better way to teach and learn science than traditional teacher-centered pedagogy (Berg et al. 2003; Furtak et al. 2012; Parappilly et al. 2013), 
students can struggle with inquiry-based learning (Berg et al. 2003), and not all instructors are well prepared to teach inquiry-based activities (Kurdziel et al. 2003). Considering the complexity of implementing inquiry-based learning in science, this study aims to understand how students perceive inquiry-based learning in the context of an undergraduate biology laboratory class. The results can inform the efforts of the science teacher as well as inspire instructors in other disciplines, seeking to maximize the benefits, while minimizing the problems students may encounter during their experiences with inquiry.

\section{Defining inquiry-based learning in science education}

The National Science Education Standards (NRC 1996) defines inquiry as a multifaceted activity

that involves making observations; posing questions; examining books and other sources of information to see what is already known; planning investigations; reviewing what is already known in light of experimental evidence; using tools to gather, analyze, and interpret data; proposing answers, explanations, and predictions; and communicating the results (23).

To connect this definition to classroom practices, researchers have proposed a categorization of inquiry-based learning activities for K-12 science classrooms (Bell, Smetana, and Binns 2005) and the undergraduate science laboratory (Buck, Bretz, and Towns 2008). Bell, Smetana, and Binns (2005) used three characteristics (i.e., question, methods, solution) to determine the level of inquiry in their framework, while Buck, Bretz, and Towns (2008) used six characteristics (i.e., problem/question, theory/background, procedures/design, results analysis, results communication, conclusions). We have chosen to base our study on the Bell, Smetana, and Binns (2005) framework because: 1) three characteristics are sufficient to capture the difference in inquiry-based activities in this study; 2) the category of authentic inquiry used by the Buck, Bretz, and Towns (2008) framework does not apply to undergraduate biology laboratories in this study; 3) the detailed description and examples for each level of inquiry used in Bell, Smetana, and Binns (2005) can be more readily adopted.

According to Bell, Smetana, and Binns (2005), there are four levels of inquiry-based learning based on whether or not the research question, method, or solution is provided. In confirmation inquiry, "students confirm a principle through an activity in which the results are known in advance" (33). Structured inquiry indicates that students "investigate a teacher-presented question through a prescribed procedure" (33). Both confirmation and structured inquiry are more traditional forms of laboratory instruction, sometimes referred to as cookbook labs, whereby the protocols are provided and there is an anticipated "correct" finding. In guided inquiry, "students investigate a teacher-presented question using student designed/selected procedures" and open inquiry starts with a student-presented question and follows with student-designed procedures (Bell, Smetana, and Binns 2005, 33).

\section{Benefits and challenges of inquiry-based learning activities in the science classroom}

Empirical studies and meta-analyses of existing studies have demonstrated the effectiveness of inquiry-based activities in post-secondary science education (Berg et al. 2003; Furtak et al. 2012; Gormally et al. 2009; Parappilly et al. 2013; Wallace et al. 2003). These studies report that students 
benefit from inquiry-based learning activities in various ways. Cognitively, students report more independent thinking during the inquiry-based learning process than during traditional cookbook labs (Parappilly et al. 2013). Affectively, students tend to report a positive attitude towards open/guided inquiry and report feeling more engaged in open/guided inquiry than traditional laboratory activities (i.e., confirmation/structured inquiry) (Berg et al. 2003).

However, inquiry-based activities do not benefit all students in the same way, and some students have negative attitudes towards inquiry-based activities (Berg et al. 2003; Cotner and Gallup 2011; Gormally et al. 2009; Parappilly et al. 2013). Some students report frustration with the complexity and uncertainty involved in open inquiry (Berg et al. 2003; Gormally et al. 2009), and some students state that too much effort and thinking are required (Deters 2005).

Existing studies of inquiry-based learning have explored teachers' perceptions of the extent and nature of inquiry (Oppong-Nuako et al. 2015). It is not clear, however, whether students' perceptions of the extent of inquiry in learning activities align with the instructor-designed levels of inquiry. Further, understanding how students define inquiry and perceive the amount of inquiry in these activities may play a role in finding solutions to existing challenges faced by students in inquiry-based learning (Berg et al. 2003; Gormally et al. 2009; Wallace et al. 2003). Following the scholarship of teaching and learning (SoTL) advocated practice of engaging students as partners in curricular design (Bovill, Cook-Sather, and Felten 2011; Felten 2013), we sought student input on their perceptions of inquiry, specifically through the lens of Self-Determination Theory (Ryan and Deci 2017), discussed below. The following research questions guided this study:

1) How do students perceive the level of inquiry in laboratory activities?

2) How do students' perceptions of inquiry differ, if at all, from the level of inquiry envisioned by the instructor?

\section{THEORETICAL FRAMEWORK}

A psychological perspective can explain why students are engaged or sometimes frustrated with learning activities with high-level inquiry. Self-Determination Theory (SDT) is a psychological theory of human motivation or engagement that has been empirically supported by studies in various fields, such as health care and physical education (Ryan and Deci 2017). SDT maintains that three basic psychological needs must be satisfied for an individual to thrive: autonomy, competence, and relatedness (Deci and Ryan 2000; Deci et al. 1991; Niemiec and Ryan 2009; Ryan and Deci 2017).

In an educational context, the need for autonomy refers to a person's perception of having choice and voice (or agency) in the learning activity; the need for competence means the person is able to master a skill or understand content within a discipline; and the need for relatedness refers to the person's feeling of being supported, valued by, and connected with others (Ryan and Deci 2017; Niemiec and Ryan 2009). These three needs work together to affect a person's motivation, learning behavior, and learning outcomes (Niemiec and Ryan 2009). In frameworks for categorizing inquirybased activities (Bell, Smetana, and Binns 2005; Buck, Bretz, and Towns 2008), the distinction among different levels of inquiry lies in how much control students have in the learning activity. Guided and open inquiry may meet a student's need for autonomy while confirmation and structured inquiry may fulfill some students' need for competence. In confirmation and structured inquiry, the content or skills are often easy to understand or master (the need for competence may be met), but some students' 
agency may be limited as they follow a step-by-step protocol (the need for autonomy may not be satisfied).

The need for competence can be used to explain students' struggle with open inquiry. Open inquiry can be intellectually challenging for students (Wu and Krajcik 2006) and lower-ability students may be overwhelmed by the uncertainty inherent in high-level inquiry (Gormally et al. 2009). This means some students' need for competence may not be met in open inquiry. An awareness of students' need for relatedness can help an instructor maximize the potential benefits - and minimize the challenges — of open/guided inquiry. In some learning environments, students are not comfortable asking for help or they are afraid to make mistakes, suggesting that their need for relatedness is unmet.

There is a need for all students, including those not intending to pursue science as a career, to become scientifically literate citizens who can understand complex issues and participate effectively in public-policy decisions (Gormally et al. 2009; Riga et al. 2017). While inquiry has been seen as a way of achieving scientific literacy (Riga et al. 2017), inquiry-based activities for students majoring in subjects other than science, technology, engineering, and math (hereafter "non-STEM") might be different than those for STEM majors (Ballen et al. 2017). Non-STEM majors tend to be less likely to see science as personally relevant, less confident in their ability to "do" science (Ballen et al. 2017), and critically, less motivated to learn science than biology majors (Glynn et al.2011). To achieve the goal of developing scientifically literate citizens, motivational aspects of the student experience should be explored. Knowledge of student motivation may help instructors design inquiry-based activities or modify existing inquiry-based curriculum to better meet students' needs and help them achieve stated learning goals.

\section{METHODS}

\section{Context}

Participants in this study were non-STEM students enrolled in an introductory biology course (The Evolution and Biology of Sex) at a large Midwestern research university in the United States (US). In most universities in the US, taking a natural science course with a laboratory component is a requirement for graduation for all students, regardless of major. It is intended to promote science literacy in a culture that has become increasingly polarized with respect to perceptions of science. This class includes a lecture and a laboratory component. Each lecture section enrolls between 120 and 200 students, and each laboratory section has between 22 and 24 students. The laboratory involves a 13-week curriculum and includes activities characterized by differing amounts of inquiry (see table 1). For example, the first lab in the curriculum is Sex and the Process of Science, which provides students with an introduction to the fundamentals of the processes of science. Specifically, students test various advertised claims about different types of condoms (e.g., do the "extra large" condoms really have greater capacity? Are the natural-skin condoms as effective a barrier as their latex or non-latex counterparts?). Students develop questions after making their own observations of condom marketing techniques, then they articulate a testable hypothesis and associated predictions, develop an experimental design with feedback from the teaching assistant (TA), execute the experiment, collect data, and finally interpret and share their results. This laboratory exercise is designated open inquiry using Bell's (2005) four-level categorization scheme. Conversely, in the second laboratory, students follow an established protocol, with a given question about evolution in action (the development of antibiotic resistance in an exposed population of bacteria) and expected results - specifically, a reduction in the zone of inhibition 
surrounding the antibiotic. According to Bell, Smetana, and Binns (2005), this is a confirmation lab exercise.

\section{Data collection}

In spring 2018, an online survey was distributed to all 426 students who had taken the introductory-biology course in fall 2017. In the survey, students were introduced to the concept of inquiry with a statement that "laboratory exercises differ in the amount of inquiry, from "cookbook"-style labs - in which procedures are fully described ahead of time, and in which the TA already knows the outcome-to complete ("open") inquiry—in which students ask the questions, design the experimental or observational procedures, and interpret novel data." Students were then asked to rate each lab activity (from the list of 13 lab activities) using a sliding scale from 0 to 100 . Next, students answered two openended questions: "Consider the lab that best reflects inquiry. What makes this lab a good example of inquiry?" and "Consider the lab that least reflects inquiry. Please explain why this lab does not involve much, if any, inquiry." To our knowledge, the students were not formally introduced to this definition of inquiry until the survey was administered.

Table 1. Weekly activities in the introductory lab and the inquiry level, as envisioned by the course instructional team, for each activity according to the four-level model of inquiry (Bell, Smetana, and Binns 2005)

$\begin{array}{lcc}\text { Lab number } & \text { Activities description } & \text { Inquiry level designed in } \\ \text { and topic } & \text { the curriculum }\end{array}$

1 (Condoms)

Sex and the Process of Science

2 (E. coli)

Evolution: Antibiotic Resistance

3 (Punnett Squares)

Genetics: Genotype

to Phenotype

4 (Mendelian Genetics)

Genetics: Meiosis

and Inheritance

5 (Biodiversity)

Biodiversity of Reproductive

Strategies
Students discuss and apply scientific methods while testing student-generated hypotheses about various types of condoms

Students measure zones of inhibition for several

Confirmation generations of $E$. coli exposed to the antibiotic triclosan

Students discuss short case studies that encourage Not inquiry an understanding of genes, alleles, and basic inheritance

Students test their understanding of meiosis and Not inquiry inheritance using Mr.

Potato Head ${ }^{\mathrm{TM}}$ models.

Students are introduced to several live (and some Not inquiry preserved) specimens, and encouraged to investigate reproductive strategies 


6(Adolescent Sexual Behavior)
Testing Hypotheses about Sex
7 (C. elegans)
Testing the Red Queen Hypothesis

8 (Sperm Competition)

Sperm Competition
Students begin multi-week research projects
focusing on adolescent sexual behavior using a large database

Students test the adaptive significance of sexual outcrossing using engineered

strains of C. elegans

Students test hypotheses about human anatomy and sperm competition

Students test a given hypothesis about HIV virulence using data from the ALIVE study

Students test their own hypotheses about factors predicting human fecundity, using a global database (Gapminder database)

11 (Group Presentation) Group Project

Presentations
Students present on their [adolescent sexual behavior] research findings

Students discuss cases that encourage an understanding of birth control and reproductive technology

Students give individual presentations demonstrating how course material is personally relevant
Open inquiry

Confirmation

Open inquiry

Confirmation

Structured inquiry

Not inquiry*

Not inquiry

Not inquiry
13 (Individual Presentation)

Final Presentations personally relevant

Note: "Not Inquiry" means that this lab does not initiate with a research question/problem, thus is not considered as an inquiry-based lab for this study. ${ }^{*}$ Week 11 presentations are the conclusion of an open-inquiry, multi-week project begun in Week 6 , thus this classification is complicated and could in fact be viewed (see results, below) as open inquiry.

Seventy-two students completed the ratings for 13 labs, and 60 students responded to the openended questions. Of 60 students' responses to two open-ended questions, three students only put the lab name for the open-end questions, offering no information on why a lab was perceived as the most/least inquiry. Therefore, only 114 responses from 57 students were used in the analysis. The survey response rate is low, at 17 percent, which may be due to the fact that the survey was administered several weeks after students completed this course, or perhaps because there was no incentive (such as points toward the final grade, or extra credit) offered to survey participants. However, there is a lot of variation in the 
data we collected, and the sample size was appropriate for our analysis. All responses were anonymous and therefore not associated with any student characteristics or performance.

\section{Data analysis}

Statistical analysis was used to describe the variation in students' ratings of inquiry, and cluster analysis grouped the labs using the amount of inquiry students perceived in each lab. Self-Determination Theory guided the qualitative analysis of students' open-ended responses. Consequently, ours is a mixedmethods research design, specifically using concurrent triangulation as quantitative and qualitative data were collected concurrently and the data were interpreted by comparing and relating the quantitative to the qualitative findings or vice versa (Warfa 2016).

\section{Quantitative analysis}

To show the general pattern in students' ratings for these lab activities, descriptive statistical analysis of 72 students' ratings for 13 labs was performed using $\mathrm{R}$. The distribution in students' ratings for the amount of inquiry in each lab activity allowed for a comparison of all lab activities. Next, cluster analysis established categories of labs based on students' perceived levels of inquiry. All labs were clustered based on students' ratings using a hierarchical clustering approach (Cornish 2007). This approach is used to identify relatively homogeneous groups of lab activities based on student ratings. Specifically, this approach uses an algorithm that starts with each lab activity as a separate cluster, and then the two closest (most similar) clusters are combined until all lab activities form one big cluster (Cornish 2007). The analysis was performed using $\mathrm{R}$ with package pvclust (Suzuki and Shimodaira 2006). Package pvclust is designed to do general hierarchical clustering rather than other bootstrapbased approaches that have been implemented mainly in phylogenetic analysis performed in bioinformatics. With this package, users can get bootstrap-based $p$-values for their own dataset and preferred clustering method. Only branches with approximately unbiased (AU) value larger than 80 are shown, which indicate moderate to strong support from the data (Suzuki and Shimodaira 2006).

\section{Qualitative analysis}

Students' responses to the two open-ended questions were coded using deductive coding (Miles, Huberman, and Saldaña 2020). Six codes were developed: autonomy supportive, competence supportive, relatedness supportive, autonomy non-supportive, competence non-supportive, and relatedness non-supportive (see table 2). The codes were assigned based on each complete sentiment to capture if the satisfaction or lack of support of multiple needs was indicated in each response. All 114 responses were coded independently by two researchers and inter-rater reliability was established using the overall Cohen's kappa. Cohen's kappa was 0.78 , indicating an adequate agreement between the raters (McHugh 2012). 
Table 2. The descriptions and example quotes for six codes that were used to interpret student open responses to questions on their perceptions of inquiry

\begin{tabular}{lll} 
Code & \multicolumn{1}{c}{ Description } & \multicolumn{1}{c}{ Example quote } \\
\hline $\begin{array}{l}\text { Autonomy } \\
\text { Supportive }\end{array}$ & $\begin{array}{l}\text { Students mention they have a voice or choice in } \\
\text { the lab, or they feel in control } \\
\text { of their learning. }\end{array}$ & $\begin{array}{l}\text { "We got to choose what to test and } \\
\text { what type of tools we wanted to use." }\end{array}$ \\
$\begin{array}{l}\text { Competence } \\
\text { Supportive }\end{array}$ & $\begin{array}{l}\text { Students mention they can understand } \\
\text { and master what they are learning, or } \\
\text { they indicate the lab activity is optimally } \\
\text { challenging for them. }\end{array}$ & $\begin{array}{l}\text { "It felt easy to track the results and the } \\
\text { experiment made sense to me." }\end{array}$ \\
$\begin{array}{l}\text { Relatedness } \\
\text { Supportive }\end{array}$ & $\begin{array}{l}\text { Students mention the interaction or closeness to } \\
\text { their peers or the TA during } \\
\text { the lab activity. }\end{array}$ & $\begin{array}{l}\text { "... and we were able to check in with } \\
\text { our TA when we needed..." }\end{array}$ \\
$\begin{array}{l}\text { Autonomy } \\
\text { Non-supportive }\end{array}$ & $\begin{array}{l}\text { Students indicate they do not have a } \\
\text { voice or choice in the lab, or they feel } \\
\text { they are being controlled. }\end{array}$ & $\begin{array}{l}\text { "...because we just copied stuff down } \\
\text { without any freedom to direct our own } \\
\text { learning." }\end{array}$ \\
$\begin{array}{l}\text { Competence } \\
\text { Non-supportive }\end{array}$ & $\begin{array}{l}\text { Students mention that they cannot understand or } \\
\text { master what they are learning, or they report that } \\
\text { the lab is } \\
\text { too easy. }\end{array}$ & $\begin{array}{l}\text { "Lab } 6 . \text { jmp [statistical software] was } \\
\text { not fun and easy to use." }\end{array}$ \\
$\begin{array}{l}\text { Students indicate a negative feeling about their } \\
\text { peers or the TA in the learning environment. }\end{array}$ & $\begin{array}{l}\text { "The gap minder lab was not very } \\
\text { engaging and the work was solely } \\
\text { between a lab partner and yourself." }\end{array}$ \\
\hline
\end{tabular}

\section{RESULTS}

Quantitative results

Variation existed in students' perceptions (or ratings) of the amount of inquiry in different laboratories (figure 1). We were initially surprised by what we felt was a misalignment between the instructor-perceived level of inquiry and student perceptions. This disconnect was especially salient with the presentation labs (labs 11 and 13, GP [Group Presentation] and IP [Individual Presentation] in figure 1). However, in the case of the group presentation lab (lab 11; GP), students are reporting on their work in the open-inquiry, Adolescent Sexual Behavior lab (lab 6; ASB [Adolescent Sexual Behavior]). Thus, it makes sense that these two lab weeks would be interpreted similarly, if not identically. The final, individual presentation (lab 13; IP) is different and not as easy to interpret; see discussion below. 
Figure 1. The box-and-whisker plot of variation in 72 students' ratings for the amount of inquiry in 13 lab activities as scheduled for each week*

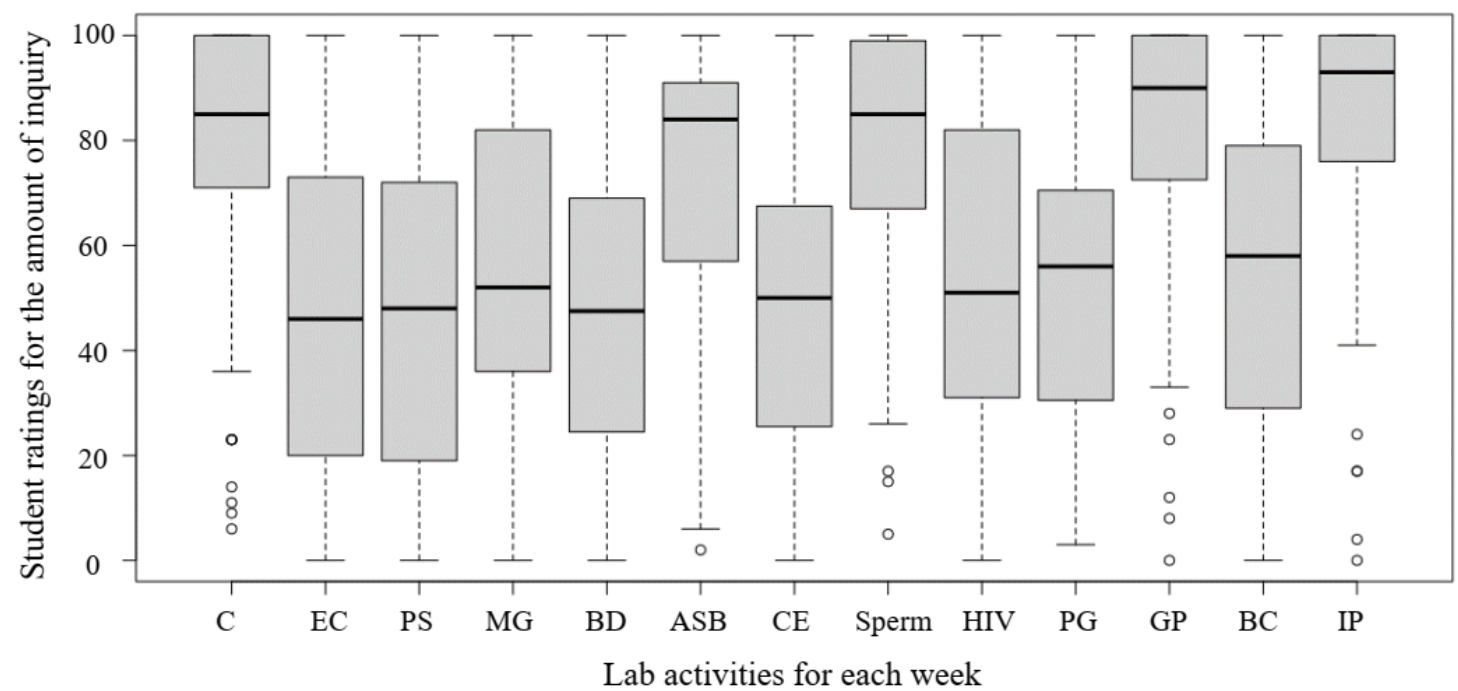

Note: The box-and-whisker plot shows the dataset in quartiles, whereby the ends of the box are the upper and lower quartiles, the median is marked by a horizontal line inside the box. 13 total lab activities: $\mathrm{C}=$ Condoms, EC $=$ E. coli, $\mathrm{PS}=$ Punnett Squares, $\mathrm{MG}=$ Mendelian Genetics, $\mathrm{BD}=$ Biodiversity, ASB = Adolescent Sexual Behavior, CE $=$ C. elegans $/$ Red Queen Hypothesis, Sperm $=$ Sperm Competition, HIV = HIV, PG = Population Growth, GP = Group Presentation, BC = Birth Control, IP = Individual Presentation).

A cluster analysis of 13 lab activities formed two main clusters - one with five lab activities, one with eight lab activities (figure 2). Five lab activities (Cluster 1) tended to have high inquiry ratings, while eight lab activities (Cluster 2) tended to have lower ratings. Open inquiry lab activities (bolded in figure 2) fell into Cluster 1, while confirmation and structured inquiry (underlined in figure 2) were in Cluster 2. The six non-inquiry lab activities (i.e., they did not start with a question/problem) were distributed across both clusters. A second cluster analysis was performed after removing students' ratings on non-inquiry labs. The three open-inquiry activities formed one cluster and the four confirmation or structured inquiry activities formed a separate cluster (figure 3). In order to simplify our interpretation, and to align our work with the goals of the lab curriculum, we removed the "presentation" labs from the second cluster. Specifically, we suspect that the presentation in week 11 is being viewed as a continuation of the Adolescent Sexual Behavior lab; this lens is valid because students are reporting on their work on this project. Thus, we can consider lab 11 ("Group Presentations") together with lab 6 ("Adolescent Sexual Behavior"). 
Figure 2. Thirteen lab activities were grouped into two main clusters based on 57 students' ratings of inquiry (15 of the 72 students did not rate all 13 activities). Lab topics in bold are open-inquiry activities while underlining indicates a confirmation or structured inquiry activity.

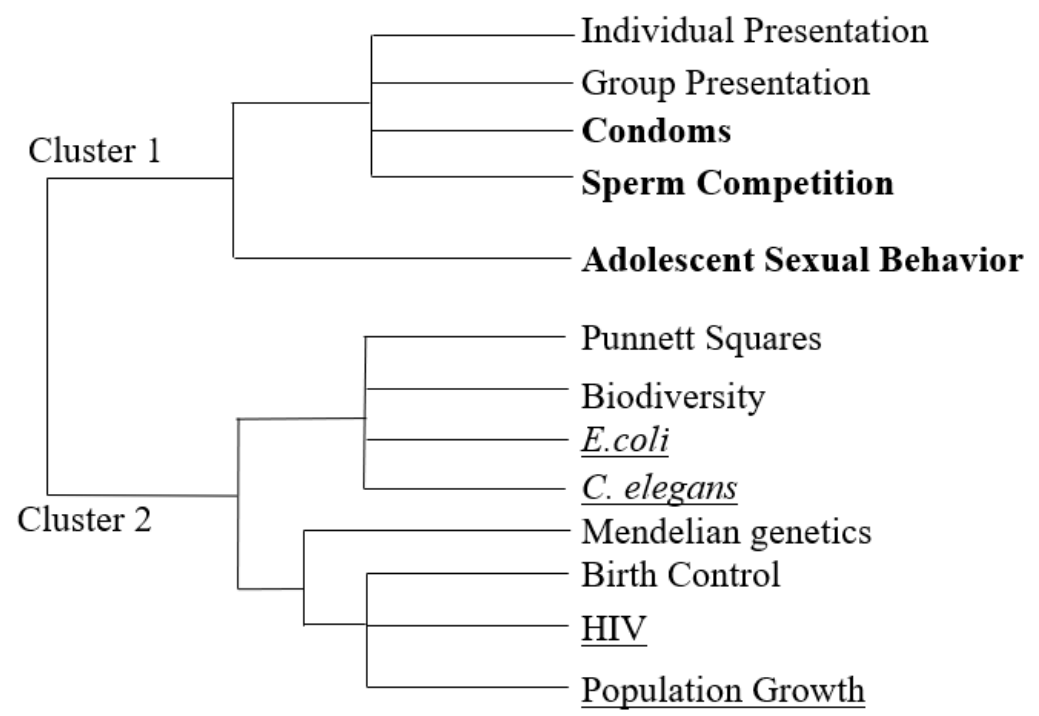

Figure 3. Cluster analysis on seven inquiry-based lab activities (Open Inquiry and Traditional) based on $\mathbf{5 7}$ students' ratings of inquiry

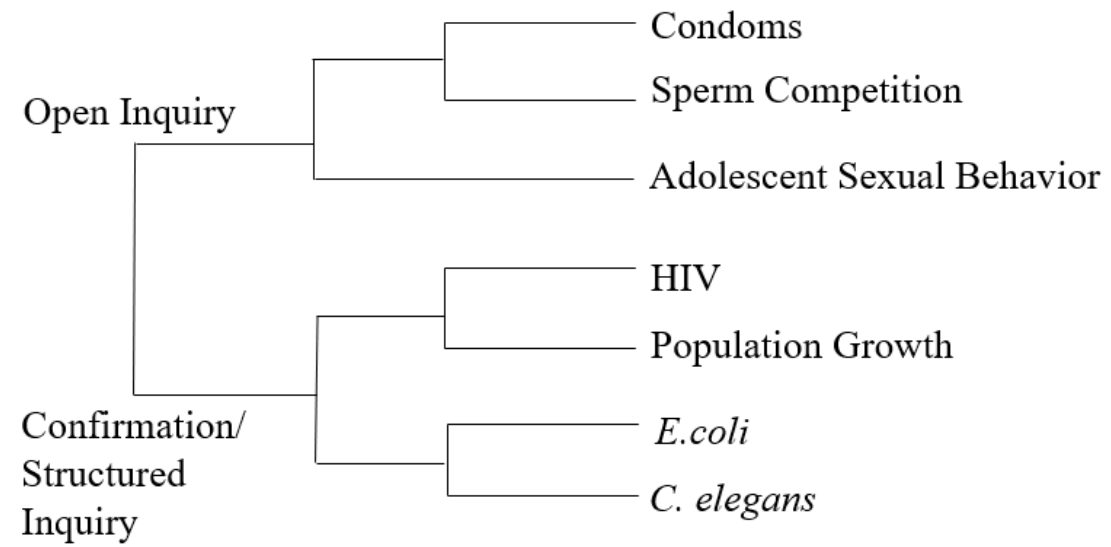

The three open-inquiry lab activities were perceived differently. Condoms and Sperm Competition labs, which are hands-on lab activities, grouped together, while Adolescent Sexual Behavior, a data-based exploration activity, formed a separate sub-branch (see figure 3). In all three lab activities, students pursued their own research questions. In the hands-on lab activities, students designed their own experiments and collected data to test their hypotheses, while in the data-based lab activity, students use an existing dataset to perform data analysis using JMP (statistics software) to test their hypotheses.

The four confirmation/structured inquiry lab activities were perceived differently. HIV and Population Growth lab activities were perceived similarly with respect to inquiry, while E. coli and C. 
elegans lab activities formed a separate branch (see figure 3). The Population Growth lab is structured inquiry in which students tested their own hypotheses about a given research question (e.g., what factors influence human population growth?) using data from the existing Gapminder (gapminder.org) database. The HIV lab is a confirmation lab in which students tested a pre-selected hypothesis about the evolution of virulence in HIV using data from an existing biomedical study. However, E. coli and C. elegans lab activities are traditional confirmation labs during which students investigated a pre-selected question and attempted to confirm an established hypothesis.

Qualitative results

The need for autonomy (supportive or non-supportive) dominated student explanations of inquiry

Student responses to the two open-ended questions were analyzed using the six codes developed from Self-Determination Theory (SDT) — whether the student responses denote support of their needs for autonomy, competence, and relatedness. Of 57 student explanations for why the activity they chose best reflects inquiry, 77 percent of student explanations indicated that their need for autonomy was supported. Fourteen percent of student explanations indicated that their need for competence was being satisfied, and less than 10 percent felt supported in their need for relatedness (figure 4a). For example, one student wrote that the Condoms lab best reflects inquiry because "it was so open ended and we were able to come up with whatever questions we wanted answered and design the experiment around that!" This quote was coded as autonomy supportive because this student stated that they have the freedom to choose what question to investigate and what procedures to follow.

Figure 4. The percentage of the six identified codes in student responses for the labs with the most (at left; $a)(n=57)$ and the least (at right; $b$ ) inquiry ( $n=57$ ). $A S=$ autonomy supportive; $C S=$ competence supportive; $R S=$ relatedness supportive; $\mathrm{AN}$ = autonomy non-supportive; $\mathrm{CN}=$ competence non-supportive; $\mathrm{RN}=$ relatedness non-supportive.

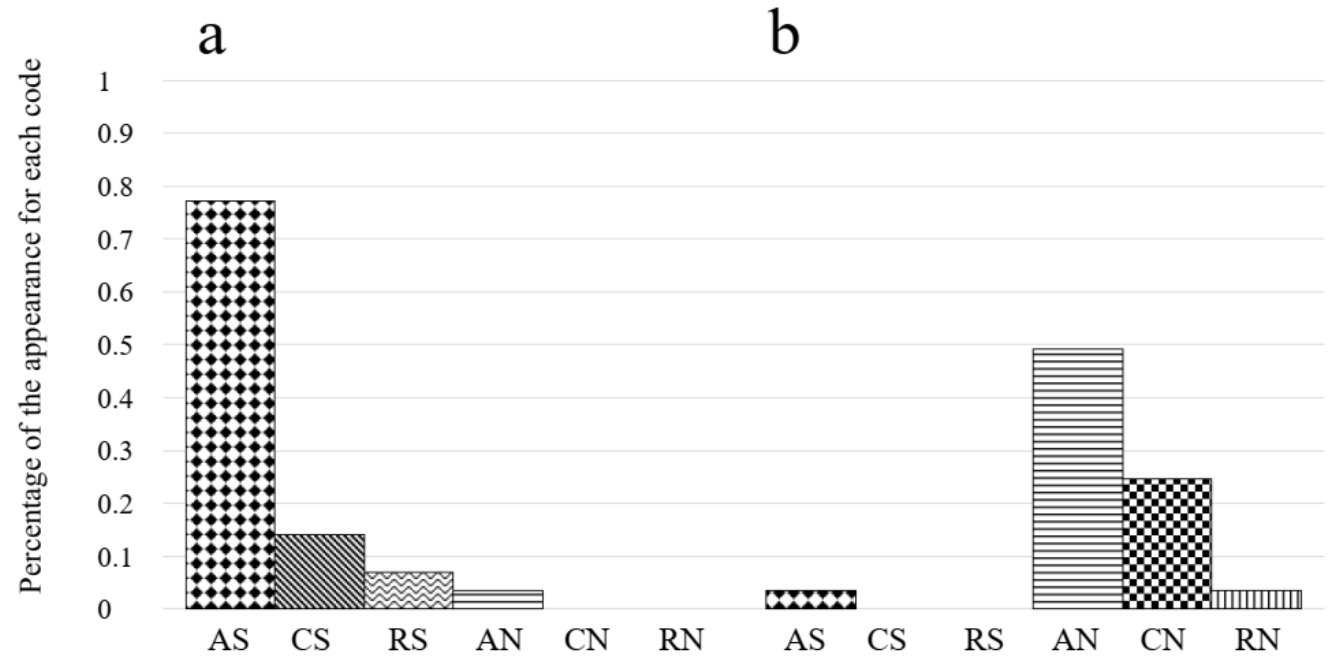

Using responses for the most inquiry lab $(n=57) \quad$ Using responses for the least inquiry lab $(n=57)$

Note: the AN code in responses for the most inquiry lab, and AS code in responses for the least inquiry lab, may be due to a student confusing the questions. 
Of 57 student responses explaining "why this lab does not involve much, if any, inquiry," 49 percent of responses indicated that the lab did not support the student's need for autonomy. Twenty-five percent were coded as competence non-supportive, and 4 percent were coded as relatedness nonsupportive (figure $4 \mathrm{~b}$ ). For example, one student indicated that their need for autonomy was unmet during the HIV activity "because we were simply following directions." "Simply following directions" indicates that students are limited in their choice of how to perform an experiment, thus, a student's need for autonomy is not supported.

\section{Students' perceptions of inquiry were connected to the need for competence}

While statements invoking autonomy dominated students' explanations, 14 percent of the students implied that their need for competence was met when explaining their perceptions of high-level inquiry, and 25 percent of the students implied that their need for competence was not met during the lab with the least inquiry. One student explained the choice of the Condoms lab as the lab that best reflects inquiry because

we get to come up with our own experiments and our own things to test. It really makes us think what we want to know and how to test it. Not only that, but it sets a foundation for more questions.

This statement indicates the satisfaction of two needs, the need for autonomy in "we get to come up with our own experiments and our own things to test" (they perceived a high degree of freedom in the activity), and the need for competence in "makes us think what we want to know" (they perceived that they can engage in an intellectual activity and understand what they are doing).

We detected two ways that students' need for competence is not supported: either they feel the learning task is too easy, or they see it as too difficult. For example, one student explained his/her choice of the Biodiversity lab as the least inquiry as "If memory serves, that was the one where we walked around the room taking notes on various creatures and it just sort of felt like data entry. Interesting information, mindless work." "Mindless work" indicated that this student's need to feel optimally challenged was not supported. Conversely, a student's negative feeling of competence was evident in the following statement "Lab 6. JMP [a statistical software] was not fun and easy to use." Although some students rated Adolescent Sexual Behavior lab as the lab with the most inquiry because of the autonomy they perceived, several students rated the Adolescent Sexual Behavior lab as the lab with the least inquiry due to the difficulty they encountered in using JMP, a statistical software. The experience with not being able to master the skills needed for the associated software indicates that the students' need for competence was not supported.

Connections between students' perceptions of inquiry and the need for relatedness

Fewer than 10 percent of the students implied a need for relatedness-whether or not they felt close to the TA or their peers - to explain their ratings for the labs with the most or least inquiry. One student wrote "we had the ability to ask and work with our TA easily and often and we were able to create our own conclusions as well" in the explanation of the sperm competition lab with the most inquiry. Being able to "work with the TA easily" indicates that the student's need for feeling supported by the people in the learning environment is met, especially when the student's need for competence was not 
satisfied. Conversely, one student explained their choice for the least inquiry lab by stating "The gap minder lab was not very engaging and the work was solely between a lab partner and yourself," indicating that the work with the partner failed to create a positive feeling, thus leading to the rating of the gap minder lab as having the least inquiry.

\section{Connecting the quantitative and qualitative data}

Student perceptions of different open-inquiry labs

Students' written explanations shed light on the clusters and sub-clusters in figure 3. From students' responses to why a lab best or least reflects inquiry, students perceive more autonomy in the hands-on, open-inquiry activities (i.e., Condoms and Sperm Competition) than in the data-based, openinquiry lab (Adolescent Sexual Behavior). All 25 comments that mentioned Condoms and Sperm Competition labs as the lab with the most inquiry reflected the satisfaction of the need for autonomy, although no student mentioned their feeling for competence or relatedness. Also, among the 57 responses for the lab with the least inquiry, Condoms or Sperm Competition lab was not listed by any student.

However, while some students perceived autonomy in the Adolescent Sexual Behavior lab, others listed this same lab as the least inquiry because "it was very much just looking at graphs and data without any of our own input." These students equated the need to collect their own data, as opposed to being provided with data sets for independent analysis, as a critical feature of inquiry. Students' perception of autonomy in the Adolescent Sexual Behavior lab was also hindered by negative perceptions of competence. As one student explained "Anything involving computers wasn't great," and another student specifically stated, "The labs that involved [the statistical software] JMP. I hated them and I couldn't get the programs to work." The difficulties in running the statistical software hindered the autonomy that was intended in this lab by the instructor. Data-based open inquiry can meet some students' need for autonomy, while it can violate other students' need for competence. We found it interesting that students rated the inquiry of the lab in which they presented on their Adolescent Sexual Behavior research somewhat higher than that of the lab in which they conducted their Adolescent Sexual Behavior research. Triangulating between the qualitative and quantitative data, we suspect that the learning curve of the statistical software countered some of the autonomy otherwise associated with open inquiry. For the presentation of their research, students were not constrained by the software, and were given autonomy to describe their work as creatively as they liked.

Similarly, students gave high inquiry marks to the final, individual presentation lab. While some of these presentations could have focused on a small research project, very few did. Students studying in the College of Design often make infographics or creative games about course topics, business majors emphasize how sex is used in marketing products, students make cakes decorated with reproductivesystem anatomy, music majors compose songs about sperm competition, and so on. Thus, this rating suggests that students are conflating autonomy with open inquiry. The fact that they were able to present on whatever they chose-within the small constraints of a few guidelines (i.e., the presentation must relate to one or more of the course topics) - made this an autonomy supportive exercise. However, from the viewpoint of the course developer, and as defined by Bell et al. (2005), this lab is not inquiry-based at all. Specifically, this lab does not start with a question about an observed natural phenomenon, and students do not engage in scientific processes_-designing experiments, collecting data, etc.—-to address 
a scientific question. Although these presentations emphasize scientific communication, which is itself a key component of science practice, they are not inquiry per se.

\section{Students' perceptions of confirmation and structured labs}

Within the group of confirmation and structured inquiry labs, the E. coli and C. elegans labs formed one subgroup, while the HIV and Population Growth labs formed another subgroup (figure 3). All comments on the E. coli and C. elegans confirmation labs reflected a lack of support for autonomy. For example, one student commented that the E. coli lab "did not have much inquiry besides the questions attached to it, because a very specific procedure needed to be followed to have success in the lab." However, students' comments on the HIV and Population Growth activities were mixed. Many comments indicated an unmet need for autonomy. For example, one student explained the choice of the Population Growth activity as the lab with the least inquiry by "we literally just answer preselected questions about a database." Conversely, another student mentioned that the Population Growth activity "allowed the most freedom of students" as they can pick "different aspects of the human population to investigate and research." Students' perceptions of the HIV lab varied, as one student wrote "The STD transmission lab because we were simply following directions," indicating the unmet need for autonomy, while another student stated that "I think the HIV transmission activity did a good job at involving the entire class, which was a nice change from partner work," which suggested that the student's need for relatedness was met. However, students' need for competence was not mentioned by any response when a confirmation or structured inquiry activity was involved.

\section{RESEARCHER POSITIONALITY}

Considering that one of the authors taught this course, it is necessary to clarify on how the positionality of researchers in this study may or may not affect the results. Cotner is the course designer and the instructor for the lab course where data were collected. For data collection, as the survey was administered several weeks after the course ended, students' responses were likely to reflect their own perception rather than to please the instructor. In the qualitative analysis, Zhao and Patrick, who have expertise both in biology and biology education, worked independently, and neither knew nor have interacted with the students. Therefore, the positionality of authors would not bias the data collection or data analysis thus to maintain the objectivity of this study.

\section{DISCUSSION}

In this work, we focused on how non-major students perceive and describe inquiry in an undergraduate biology lab course with 13 weeks of different lab activities. We were especially interested in student perceptions of inquiry from a motivational standpoint and used Self-Determination Theory as our framework for understanding students' statements about inquiry.

As defined in this study and previous studies (Bell et al. 2005; Buck et al. 2008), a lab exercise's level of inquiry can be determined in part by how much autonomy students have in the lab activity. In general, students in our study interpreted a laboratory's degree of inquiry by how much autonomy they felt. Students frequently used terms like "freedom" and "own experiment" to explain their choices for the labs with the most inquiry. However, we found that students did not always perceive autonomy in open inquiry labs in which data were provided for independent analysis. Some students may equate inquiry with designing their own procedures for data collection. While recent work suggests that students 
majoring in biology can engage in data-mining research projects and perceive these investigations as authentic inquiry (Kirkpatrick et al. 2019), our findings imply that non-biology majors may not fully appreciate the legitimate scientific value in existing datasets and may perceive hands-on activities as more authentic. Explicit discussion with students about the nature of scientific inquiry could help students to understand the authentic nature of such activities. Providing a meaningful rationale is a compelling way to increase the autonomy-supportiveness of a learning environment, especially when choice is not possible (Ryan and Deci 2017). In addition, giving students examples of how databases have been used to drive real research could help validate this type of investigation.

Another reason that students struggled to see autonomy in the data-based open inquiry is that the statistical software was difficult to use, thus an initial need for competence was not met. Without the necessary skills to perform the experimental tasks, it is possible that many students struggled to benefit from this open-inquiry activity. This finding aligns with Berg et al.'s (2003) report that some students need more support and feedback from the instructor to succeed in an inquiry-based laboratory. Further, this disconnect affirms that a Self-Determination Theory perspective can help us, as instructors, when we are developing our inquiry-based labs.

Although inquiry-based labs are valued for being autonomy-supportive, confirmation lab activities, such as the E. coli or C. elegans labs in this study, are included in the course to achieve specific learning goals, such as developing familiarity with fundamental principles in biology and the widely used model organisms of biology. It is true that students tended to report a lack of autonomy in performing these two activities, but they also can disentangle competence from autonomy. For example, one student wrote, "They just threw instructions at us in the book and we followed step by step. Which I like ... It ensures that learning will take place and reduces confusion." Even in implementing lower-level inquiry, it is possible to engage students by creating an interactive learning environment, or by offering as many choices as the curriculum can allow.

\section{LIMITATIONS}

This study was performed in one class, in one discipline, in one university; thus, the results may not be generalizable to other contexts. Students' perceptions of the challenges in these laboratory activities may be affected by their non-biology background. Studies of students from different disciplines and from different institutions may provide a more generalizable conclusion on the interpretation of students' perceptions of inquiry.

\section{IMPLICATIONS}

Our initial aim was to help instructors use knowledge of student motivation when designing inquiry-based activities or modifying existing curricula. Understanding student motivation should allow us to better meet students' needs and help them achieve specified learning goals. SDT provides a useful framework for both designing inquiry-based learning activities and diagnosing lab exercises and other learning activities in need of improvement.

Our findings reveal that students can largely distinguish between types of inquiry, and their rankings of lab activities based on inquiry mostly align with those of the course developer. We also found that, in open-inquiry lab exercises, autonomy is key to the student experience, with the majority of the comments aligned to the "autonomy supportive" code category. These findings echo our previous work (Ballen et al. 2018; Kirkpatrick et al. 2019) and that of other researchers in both biology education 
research and the scholarship of teaching and learning (Hanauer et al. 2018; Jang, Reeve, and Halusic 2016; Rodrigo-Peiris, Xiang, and Cassone 2018) — suggesting that with inquiry-based learning, one size does not fit all. The current work suggests that some students should have their need for competence met as an initial requirement in order to experience autonomy or work successfully in an autonomysupportive environment. According to Self-Determination Theory, Aelterman et al. (2019) propose that setting up clear expectations or guidelines, adjusting the difficulty level of learning activities to students' skills, or providing positive feedback to students will foster students' competence. With students' motivational demands for autonomy and competence being met, they can realize the benefits of openinquiry lab investigations. Similarly, some instructors may find that traditional labs are useful for providing students with the necessary tools to start generating and testing their own hypotheses. This form of structure (Cheon, Reeve, and Vansteenkiste 2020; Jang, Reeve, and Deci 2010), or scaffolding, may be especially useful in a non-major setting, or with students lacking background experiences in science. Critically, the "sweet spot" is autonomy plus structure, especially for novice learners (Jang, Reeve, and Deci 2010).

Further, student input suggests that students value autonomy in lab activities and devalue labs that do not provide support for individual decision-making and agency. Thus, instructors constrained to implement traditional labs throughout the curriculum - for whatever reasons - should work to make these lab exercises more autonomy-supportive. Students could be given choice, voice, and agency in how they present their findings. Or perhaps after a confirmation lab exercise, students could suggest ideas for future research projects to develop their work-even if they do not have the opportunity to actually pursue the research.

Finally, we are encouraged by the potential of the SDT framework to both design inquiry-based activities and diagnose problems within an existing laboratory curriculum. We encourage our colleagues designing for inquiry-based learning to consider their students' demands for relatedness, competenceand critically-autonomy, as they develop and implement the curriculum.

\section{ACKNOWLEDGEMENTS}

This material is based upon work supported by the National Science Foundation under Grant 1540789 and Grant 1432414. The collaboration was forged in part by SEISMIC_-Sloan Equity and Inclusion in STEM Introductory Courses. Any opinions, findings, and conclusions or recommendations expressed in this material are those of the author(s) and do not necessarily reflect the views of the National Science Foundation.

Fangfang Zhao is an assistant professor in the School of Teacher Education, Nanjing Normal University (CHN). Her work focuses on modelling in science education, biology teaching and learning, and biology teacher preparation.

Gillian Roehrig is a professor in the College of Education and Human Development at the University of Minnesota (USA). Her research explores issues of professional development for $K$ - 12 science teachers, with a focus on implementation of integrated STEM learning environments.

Lorelei Patrick is an assistant professor in the Department of Biological Sciences, Fort Hays State University (USA). She studies student and faculty perceptions of evidence-based teaching practices and strategies to effectively train teaching assistants. 
Chantal Levesque-Bristol is the Executive Director Center for Instructional Excellence and Professor of Educational Psychology, Purdue University (USA). Her research area is focused on motivation applied to education and teaching and learning.

Sehoya Cotner is a professor in the Department of Biological Sciences at the University of Bergen (NOR), and has an adjunct position in the Department of Biology Teaching and Learning at the University of Minnesota (USA). Her research focuses on active learning, STEM equity, and student-active research in higher education

\section{REFERENCES}

Abdulwahed, Mahmoud, and Zoltan K. Nagy. 2009. "Applying Kolb's Experiential Learning Cycle for Laboratory Education." Journal of Engineering Education 98, no. 3: 283-94.

Aelterman, Nathalie, Maarten Vansteenkiste, Leen Haerens, Bart Soenens, Johnny RJ Fontaine, and Johnmarshall Reeve. 2019. "Toward an Integrative and Fine-Grained Insight in Motivating and Demotivating Teaching Styles: The Merits Of A Circumplex Approach." Journal of Educational Psychology 111, no. 3: 497.

Ballen, Cissy J., Jessamina E. Blum, Sara Brownell, Sadie Hebert, James Hewlett, Joanna R. Klein, Erik A. McDonald, Denise L. Monti, Stephen C. Nold, Krista E. Slemmons, Paula A. G. Soneral, and Sehoya Cotner. 2017. "A Call to Develop Course-Based Undergraduate Research Experiences (CUREs) for Nonmajors Courses." CBELife Sciences Education, 16 no. 2: $\mathrm{mr} 2,1-7$.

Ballen, Cissy J., Seth K. Thompson, Jessamina E. Blum, Nicholas P. Newstrom, and Sehoya Cotner. 2018. "Discovery and Broad Relevance May Be Insignificant Components of Course-Based Undergraduate Research Experiences (CUREs) for Non-Biology Majors." Journal of Microbiology and Biology Education 19, no. 2, 1-9.

Bell, Randy L., Lara Smetana, and lan Binns. 2005. "Simplifying Inquiry Instruction." The Science Teacher 72, no. 7: 30-33.

Berg, C. Anders R., V. Christina B. Bergendahl, Bruno Lundberg, and Lena Tibell. 2003. "Benefiting From an OpenEnded Experiment? A Comparison of Attitudes to, and Outcomes of, an Expository Versus an Open-Inquiry Version of the Same Experiment." International Journal of Science Education 25, no. 3: 351-72.

Bovill, Catherine, Alison Cook-Sather, and Peter Felten. 2011. "Students as Co-Creators of Teaching Approaches, Course Design, and Curricula: Implications for Academic Developers." International Journal for Academic Development 16, no. 2: 133-45.

Buck, Laura B., Stacey Lowery Bretz, and Marcy H. Towns. 2008. "Characterizing the Level of Inquiry in the Undergraduate Laboratory." Journal of College Science Teaching 38, no. 1:52-58.

Cheon, Sung Hyeon, Johnmarshall Reeve, and Maarten Vansteenkiste. 2020. "When Teachers Learn How to Provide Classroom Structure in an Autonomy-Supportive Way: Benefits to Teachers and Their Students." Teaching and Teacher Education 90: 103004.

Cornish, Rosie. 2007. "Cluster Analysis.” Mathematics Learning Support Centre. Retrieved from http://www.statstutor.ac.uk/resources/uploaded/clusteranalysis.pdf.

Cotner, Sehoya, and Gordon G. Gallup Jr. 2011. "Introductory Biology Labs... They Just Aren't Sexy Enough!" Bioscience Education 18, no. 1: 1-11.

Deci, Edward L., and Richard M. Ryan. 2011. "The "What" and "Why" of Goal Pursuits: Human Needs and the SelfDetermination of Behavior." Psychological Inquiry 11, no. 4: 227-68.

Deci, Edward L., Robert J. Vallerand, Luc G. Pelletier, and Richard M. Ryan. 1991. "Motivation and Education: The Self-Determination Perspective." Educational Psychologist 26, no. 34: 325-46.

Deters, Kelly Morgan. 2005. "Student Opinions Regarding Inquiry-Based Labs." Journal of Chemical Education 82, no. 8: 1178.

Felten, Peter. 2013. "Principles of Good Practice in SoTL." Teaching \& Learning Inquiry 1, no. 1: 121-25.

Ferri, Bonni H., Aldo A. Ferri, David M. Majerich, and Amanda G. Madden. 2016. "Effects of In-Class Hands-On Laboratories in a Large Enrollment, Multiple Section Blended Linear Circuits Course." Advances in Engineering Education 5, no. 3: 1-27.

Furtak, Erin Marie, Tina Seidel, Heidi Iverson, and Derek C. Briggs. 2012. "Experimental and Quasi-Experimental Studies of Inquiry-Based Science Teaching: A Meta-Analysis." Review of Educational Research 82, no. 3: 300-329.

Glynn, Shawn M., Peggy Brickman, Norris Armstrong, and Gita Taasoobshirazi. 2011. "Science Motivation Questionnaire II: Validation with Science Majors and Nonscience Majors." Journal of Research in Science 
Teaching 48, no. 10: 1159-76.

Gormally, Cara, Peggy Brickman, Brittan Hallar, and Norris Armstrong. 2009. "Effects of Inquiry-Based Learning on Students' Science Literacy Skills and Confidence." International Journal for the Scholarship of Teaching and Learning 3, no. 2: n2.

Hanauer, David I., Justin Nicholes, Fang-Yu Liao, Aaron Beasley, and Heather Henter. 2018. "Short-Term Research Experience (SRE) in the Traditional Lab: Qualitative and Quantitative Data on Outcomes." CBE-Life Sciences Education 17, no. 4: ar64.

Jang, Hyungshim, Johnmarshall Reeve, and Edward L. Deci. 2010. "Engaging Students in Learning Activities: It is Not Autonomy Support or Structure but Autonomy Support and Structure." Journal of Educational Psychology 102, no. 3: 588.

Jang, Hyungshim, Johnmarshall Reeve, and Marc Halusic. 2016. "A New Autonomy-Supportive Way of Teaching That Increases Conceptual Learning: Teaching in Students' Preferred Ways." The Journal of Experimental Education 84, no. 4: 686-701.

Kirkpatrick, Catherine, Anita Schuchardt, Daniel Baltz, and Sehoya Cotner. 2019. "Computer-Based and BenchBased Undergraduate Research Experiences Produce Similar Attitudinal Outcomes." CBE-Life Sciences Education 18, no. 1: ar10,1-11.

Kolb, Alice Y., and David A. Kolb. 2005. "Learning Styles and Learning Spaces: Enhancing Experiential Learning in Higher Education." Academy of Management Learning and Education 4, no. 2: 193-212.

Kurdziel, Josepha P., Jessica A. Turner, Julie A. Luft, and Gillian H. Roehrig. 2003. "Graduate Teaching Assistants and Inquiry-Based Instruction: Implications for Graduate Teaching Assistant Training." Journal of Chemical Education 80, no. 10: 1206.

McHugh, Mary L. 2012. "Interrater Reliability: The Kappa Statistic." Biochemia Medica 22, no. 3: 276-82.

Miles, Matthew B., Michael A. Huberman, and Johnny Saldaña. 2020. Qualitative Data Analysis: A Methods Sourcebook. Sage publications.

National Research Council (NRC). 1996. National Science Education Standards. National Academies Press.

Niemiec, Christopher P., and Richard M. Ryan. 2009. "Autonomy, Competence, and Relatedness in the Classroom: Applying Self-Determination Theory to Educational Practice." Theory and Research in Education 7, no. 2: 133-44.

Oppong-Nuako, Juliet, Bruce M. Shore, Katie S. Saunders-Stewart, and Petra D. T. Gyles. 2015. "Using Brief Teacher Interviews to Assess The Extent of Inquiry in Classrooms." Journal of Advanced Academics 26, no. 3: 197-226.

Parappilly, Maria, B, Salim Siddiqui, Marjan G. Zadnik, Joe Shapter, and Lisa Schmidt. 2013. "An Inquiry-Based Approach to Laboratory Experiences: Investigating Students' Ways of Active Learning." International Journal of Innovation in Science and Mathematics Education, 21, no. 5: 42-53.

Riga, Fran, Mark Winterbottom, Harris, E., and Newby, L. 2017. "Inquiry-Based Science Education." In B. Taber, K. S., Akpan (Ed.), Science Education: An International Course Companion. Rotterdam, The Netherlands: Sense Publishers. 247-61.

Rodrigo-Peiris, Thushani, Lin Xiang, and Vincent M. Cassone. 2018. "A Low-Intensity, Hybrid Design Between a "Traditional" and a "Course-Based" Research Experience Yields Positive Outcomes for Science Undergraduate Freshmen and Shows Potential for Large-Scale Application." CBE_Life Sciences Education 17, no. 4: ar53, 1-18.

Rosen, Spencer, Sabrine Griffith, Eli Byrnes, Steven Michael Santana, Laura Palucki Blake, and Matthew Spencer. 2019. "Relating Level of Inquiry in Laboratory Instructions to Student Learning Outcomes." In Proc. ASEE Annual Conference and Exposition, Conference Proceedings. 1-14.

Ryan, Richard M., and Edward L. Deci. 2017. Self-Determination Theory: Basic Psychological Needs in Motivation, Development, and Wellness. Guilford Publications.

Suzuki, Ryota, and Hidetoshi Shimodaira. 2006. "Pvclust: An R Package for Assessing the Uncertainty in Hierarchical Clustering." Bioinformatics 22, no. 12: 1540-42.

Wallace, Carolyn S., Mai Yin Tsoi, Jamie Calkin, and Marshall Darley. 2003. "Learning From Inquiry-Based Laboratories in Nonmajor Biology: An Interpretive Study of the Relationships Among Inquiry Experience, Epistemologies, and Conceptual Growth." Journal of Research in Science Teaching 40, no. 10: 986-1024.

Warfa, Abdi-Rizak M. 2016. "Mixed-Methods Design in Biology Education Research: Approach and Uses." CBE- 
Life Sciences Education 15, no. 4: rm5, 1-11.

Wu, Hsin-Kai, and Joseph S. Krajcik. 2006. "Inscriptional Practices in Two Inquiry-Based Classrooms: A Case Study of Seventh Graders' Use of Data Tables and Graphs." Journal of Research in Science Teaching 43: 63-95.

\section{(c) (i) (5)}

Copyright for the content of articles published in Teaching \& Learning Inquiry resides with the authors, and copyright for the publication layout resides with the journal. These copyright holders have agreed that this article should be available on open access under a Creative Commons Attribution License 4.0 International (https://creativecommons.org/licenses/by-nc/4.0/). The only constraint on reproduction and distribution, and the only role for copyright in this domain, should be to give authors control over the integrity of their work and the right to be properly acknowledged and cited, and to cite Teaching \& Learning Inquiry as the original place of publication. Readers are free to share these materials - as long as appropriate credit is given, a link to the license is provided, and any changes are indicated. 